\title{
A implantação dos Postos de Informação de Triatomíneo no município de Santana de Pirapama/MG
}

\author{
Patrícia Aparecida da Silva Pereira*
}

*Enfermeira, especialização em Urgência e Emergência e Trauma pela Pontifícia Universidade Católica de Minas Gerais - PUC Minas, Apoiadora do Programa Nacional de Melhoria do Acesso e da Qualidade na Atenção Básica - PMAQ e Programa Saúde na Escola-PSE, Educadora em Saúde para a Vigilância em Saúde e Atençâo Básica

\begin{abstract}
Resumo
No Brasil, um dos maiores programas de controle de endemias é o Programa de Controle da Doença de Chagas (PCDCh). Uma importante estratégia desse programa é o Posto de Informação de Triatomíneo (PIT), em Santana de Pirapama, localizada na região central de Minas Gerais, que foi adotada no ano de 2011. A partir do exposto, a questão norteadora da presente monografia foi saber qual foi o impacto referente ao controle do vetor no município de Santana de Pirapama após a implantação dos PIT? Para responder a esta questão, foi utilizada a pesquisa documental, com o objetivo geral de verificar a efetividade da implantação dos PIT no município de Santana de Pirapama. Teve como objetivos específicos descrever a implantação dos PIT e analisar a estratégia utilizada junto à populaçáo para o alcance do controle do vetor. De acordo com a pesquisa, foram identificados 130 Triatomíneos, desses, cinco espécies diferentes. Nesse sentido, percebe-se que foi essencial o trabalho de educaçáo em saúde para o alcance desses resultados, mas, para manter essa estratégia em pleno funcionamento, serão essenciais alguns itens, tais como: recursos humanos, recursos materiais e educação em saúde.
\end{abstract}

Palavras-chave: doença de Chagas, triatominae, controle de vetores.

\section{Abstract}

\section{The implantation of the triatomine information posts in Santana Pirapama/MG}

In Brazil, one of the biggest control programs for endemics is the Chagas Disease Control Program (PCDCh). An important strategy of this program is the Triatomine Information Post (PIT), in Santana de Pirapama, located in the central region of Minas Gerais, which was adopted in 2011. From the exposed, the guiding question of the present study was to know what was the related impact to the vector's control in the Santana de Pirapama country after the implantation of the PIT? To answer this question, it was used the documents research, aiming at checking the efficiency of the implantation of the PIT in Santana de Pirapama. The specific goals were to describe the implantation of the PIT and to analyze the strategy used with the population to reach vector's control. According to the research, 130 triatomines were identified, of these, 5 different species. Therefore, we noticed that health educational work was essential to reach these results, but 
to keep this strategy fully functioning it will be essential for some areas, such as: human resources, material resources and health education.

Key-words: Chagas disease, triatomine, vector's control.

\section{Resumem}

\section{La implementación de Información de los Puestos de Triatomineo en el municipio de Santana Pirapama/MG}

En el Brasil, uno de los programas más importantes para el control de enfermedades endémicas es el Programa para el Control de la Enfermedad de Chagas (PCDCh). Una estrategia importante de este programa es el Puesto de Información de Triatomineo (PIT), en Santana Pirapama, ubicada en la región central del Estado de Minas Gerais, que fue aprobada en el ańo 2011. A partir de lo expuesto, la pregunta orientadora de esta monografía fue saber el impacto en el control del vector en el municipio de Santana Pirapama tras la implementación de los PIT? Para responder a esta pregunta, se utilizó la investigación documental, con el objetivo general de verificar la eficacia de la implementación de los PIT en el municipio de Santana Pirapama y como objetivos específicos describir la implantación de los PIT y analizar la estrategia utilizada por la población para alcanzar el control del vector. Según la encuesta, se identificaron 130 Triatominos, de estos, cinco especies diferentes. En este sentido, es evidente que fue esencial el trabajo de educación en la esfera de la salud para el alcance de estos resultados, pero para mantener esta estrategia en pleno funcionamiento será esencial algunos elementos, tales como: recursos humanos, recursos materiales y la educación para la salud.

Palabras-chave: enfermedad de Chagas, triatominae, control de vectores.

\section{Introdução}

A doença de Chagas é resultado de uma infecção causada pelo Trypanosoma Cruzi. A doença foi descoberta na cidade de Lassance, no norte de Minas Gerais, em abril de 1909. Seu descobridor foi Carlos Chagas, quando foi designado por Oswaldo Cruz no ano de 1907, para auxiliar no combate a uma epidemia de Malária na região do Rio das Velhas, que fica entre a cidade de Corinto e a cidade de Pirapora no estado de Minas Gerais [1].

Segundo Brasil [2], “[...] a transmissão natural, ou primária, da doença de Chagas é a vetorial, que se dá através das fezes dos triatomíneos, também conhecidos como "barbeiros" ou "chupóes"”. Os Triatomíneos são infectados quando se alimentam de um dos variados hospedeiros existentes em uma determinada área, bastando que este hospedeiro seja um mamífero e que esteja infectado e assim transmitindo a doença aos outros mamíferos, inclusive ao homem [3].

Nesse sentido, o Programa de Controle da Doença de Chagas (PCDCh) é um grande aliado no controle do vetor, sendo ele um dos maiores programas de controle de endemias no Brasil, foi criado pela Superintendência de Campanhas de Saúde Pública (SUCAN), depois Fundação
Nacional de Saúde (FUNASA) do Ministério da Saúde (MS), teve suas bases técnicas definidas na década de 1940, mas somente em 1975 o programa teve alcance nacional, e a partir daí começou a ser estruturado como um programa de controle, do qual foi se adequando de acordo com as necessidades em campo, o que consiste em busca ativa de triatomíneos e borrifação $[4,5]$.

Dentro desse programa, há uma estratégia importante no controle do vetor, o Posto de Informação de Triatomíneo (PIT), que foi criado na década de 80 para facilitar o acesso da comunidade às açóes de Vigilância em Saúde e implantado pela Secretaria Municipal de Saúde para atender a uma determinada área que se queira fazer vigilância [6].

A partir do risco existente em uma determinada área ou município, medidas adequadas de prevençáo e controle da doença se fazem necessárias. Para isso, a participação popular é imprescindível, aumentando o conhecimento das pessoas a respeito da prevenção e controle de Triatomíneos. Orientar sobre o encaminhamento de insetos suspeitos à Unidade Básica de Saúde (UBS) ou ao Posto de Identificação de Triatomíneo (PIT) mais próximo [3].

O estado de Minas Gerais apresenta risco elevado para a transmissão da doença de Chagas, 
por meio de vetores, da espécie dos Triatomíneos [3]. Nesse sentido, muitos municípios estáo sob vigilância do Programa de Controle da Doença de Chagas (PCDCh), dos quais apresentam um índice de dispersão vetorial abaixo de 5\% [5].

Sabe-se, contudo, que o município de Santana de Pirapama, regiáo central de Minas Gerais, fica localizada em área de médio risco de reinfestação vetorial da Doença de Chagas, segundo a Estratificação dos Municípios do PCDCh pela Secretaria Estadual de Saúde (SES/MG) e dividido por Superintendência Regional de Saúde (SRS). Ver Mapa abaixo:

Estratificação dos Municípios do PCDCh, segundo o Grau de Risco de Reinfestação, por GRS's

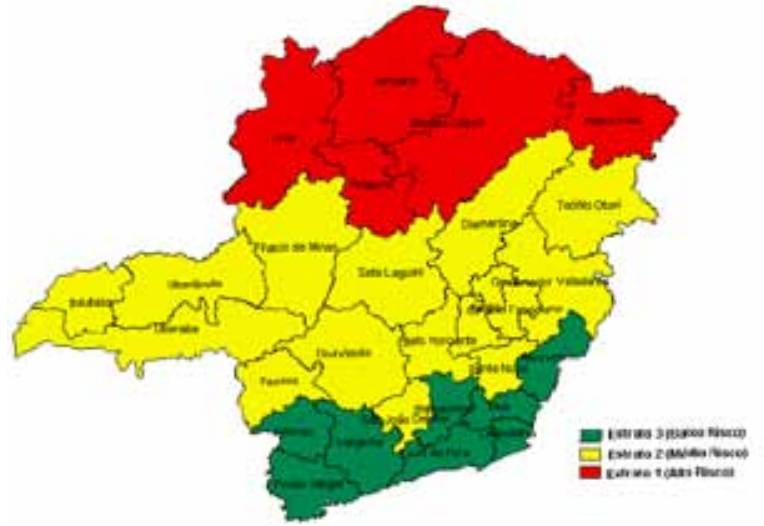

Fonte: Secretaria Estadual de Saúde - SES/MG [7].

Santana de Pirapama possui área territorial de $1.256 \mathrm{~km}^{2}$ e tem população de 8.004 habitantes e seu bioma é o cerrado [8]. É considerada a Cidade do Turismo Ecológico pelas suas belas paisagens naturais em cachoeiras [9], é enriquecido por campos rupestres [10] e está situado a $154 \mathrm{~km}$ da capital do Estado de Minas Gerais, Belo Horizonte [9]. É um município com histórico de Doença de Chagas e a constante presença de Triatomíneos encaminhados ao serviço de Epidemiologia.

Contudo, até o ano de 2011, não havia nenhuma intervenção plausível no sentido de controlar o vetor, necessitando de uma estratégia eficaz no controle vetorial. Desta forma, foram implantados vários PIT's dentro do município de Santana de Pirapama, com o intuito de controlar a incidência de novos casos de doença de Chagas por transmissão vetorial na região.

Diante disso, propôs-se por meio de pesquisa documental, verificar a efetividade dos PIT's im- plantados no município de Santana de Pirapama, analisando todas as notificações que chegaram a esses Postos de Informação de Triatomíneo no período compreendido entre novembro de 2011 e julho de 2012.

O objetivo do presente estudo é descrever a implantação dos PIT e analisar a estratégia adotada junto à populaçáo para o controle do Triatomíneo no município de Santana de Pirapama/MG.

A questáo norteadora da presente pesquisa foi saber qual foi o impacto referente ao controle do vetor no município de Santana de Pirapama após a implantação dos PIT?

\section{Material e métodos}

A linha de pesquisa abordada no presente estudo foi a Prevençấo e Controle de Agravos à Saúde, que compreende o controle e a prevenção de doenças infecciosas e parasitárias, doenças crônicas degenerativas, problemas nutricionais e de mortalidade.

Para responder ao problema, foi utilizada a pesquisa documental que, segundo Marconi e Lakatos [11], "[...] visa à coleta de dados por meio de documentos, sejam eles escritos ou não, é considerada fonte primária e pode ser utilizada no momento em que um fato acontece ou depois deste realizado". Neste caso se trata de uma pesquisa pós-fato, ou seja, depois da implantação dos PIT.

A implantação desses Postos iniciou em julho de 2011 e durou cerca de quatro meses, totalizando treze PIT distribuídos por todo o município nos núcleos de localidades. Essa distribuição tem como objetivo facilitar o acesso e disseminar informaçóes aos moradores do seu PIT de referência. Assim, o morador quando achar um inseto suspeito de ser um Triatomíneo levará para o PIT mais próximo.

De acordo com os documentos, foram realizadas doze reunióes comunitárias na zona rural do município e uma reuniáo na zona urbana, incrementadas com açóes de Educação em Saúde, realizada pela pesquisadora que também era acadêmica de enfermagem, alocada no município no período da pesquisa, e com o auxílio dos Agentes de Saúde Pública e do Coordenador de Endemias de Santana do Pirapama. Foi discutido com a população sobre a importância da implantação dos PIT para o controle vetorial. 
A partir do exposto, essa pesquisa verificou a efetividade de cada PIT por meio da Pesquisa Documental. Foram analisados todos os boletins do Programa de Controle da Doença de Chagas (PCDCh) utilizados no município de Santana de Pirapama, como: Diário de Pesquisa e Borrifação e o Formulário de Exames de Triatomíneos. Para isso foi necessário uma minuciosa verificação de todos esses boletins, quantificando os dados de mesma categoria, assim, foram coletadas as informaçóes assinaladas pelos Agentes de Controle de Endemias (ACE) nesses documentos.

Por meio desses documentos, foi possível somar as atividades de controle do Triatomíneo realizadas no município. São elas: Pesquisa, Borrifação; Visita ao PIT sem notificação; Visita ao PIT com notificação; e Atendimento a notificação. Também pelos documentos foi possível extrair dados como o tipo de parede e telha predominantes no município. E ainda, o local de captura do Triatomíneo e se foi no intra ou peridomicílio, dentre outras informações.

Assim, foram verificadas todas as notificaçóes recebidas no município, desde o término das implantaçóes dos PIT, em outubro, até a coleta dos dados, ocorridos na primeira semana de agosto de 2012. O tempo após a implantação dos PIT para a avaliação foi de nove meses.

Os arquivos pesquisados foram de ordem pública do serviço de Epidemiologia da Secretaria Municipal de Saúde de Santana de Pirapama e para tal contou-se com a permissão do prefeito para acessá-los, por meio de Termo de Consentimento Livre e Esclarecido (TCLE).

Para fundamentar este estudo foi necessária uma revisáo bibliográfica acerca do tema. Os descritores utilizados para a pesquisa foram: Doença de Chagas; Triatominae; e Controle de Vetores, todos inseridos na lista oficial dos Descritores em Ciências da Saúde (DECS), disponibilizado na página eletrônica da Biblioteca Virtual da Saúde (BVS) - Bireme.

As bases de dados utilizados para a pesquisa foram: Revistas de Saúde Pública; Revistas da Sociedade Brasileira de Medicina Tropical; entre outras, por meio do Scientific Electronic Library Online - Scielo e da Biblioteca Virtual da Saúde - BVS, além de artigos e manuais examinados dos sites da Fundação Oswaldo Cruz - Fiocruz, da Secretaria Estadual de Saúde (SES) de Minas Gerais, Rio de Janeiro e do Rio Grande do Sul.
Depois de selecionados alguns artigos, os resumos foram lidos para identificação do conteúdo que estivessem de acordo com o embasamento da pesquisa. Foram utilizados para tal, quinze artigos, entre outros materiais didáticos como: manual, portaria, dissertação, tese, guias epidemiológicos do MS, e alguns sites de interesse para a presente monografia.

Os critérios de inclusão dos artigos foram definidos em função do tema "Posto de Informação de Triatomíneo - PIT", além da abordagem do conteúdo de interesse para a descrição das implantaçóes do PIT no município, como as açóes de educação em saúde em torno da Doença de Chagas; outro critério foi a inclusão de artigos que fossem da língua portuguesa.

Outras informações referentes ao estado entomológico do município de Santana de Pirapama também foram necessárias para complementar a presente pesquisa. Essas informaçóes foram buscadas na Superintendência Regional de Saúde de Sete Lagoas SRS/SL, com a Coordenadora do Núcleo de Vigilância Epidemiológica Ambiental e Saúde do Trabalhador, Sra Fransbel Silva Albuquerque e toda a sua equipe de trabalho que atende ao município de Santana de Pirapama. Essa busca foi necessária devido à ausência de fontes de dados escritos ou sistematizados com relaçáo ao controle de Triatomíneos no município.

Esta pesquisa foi encaminhada ao Comitê de Ética em Pesquisa (COEP), através da Plataforma Brasil no site do Ministério da Saúde e foi submetida à apreciaçáo. $\mathrm{O}$ presente estudo atendeu às determinaçóes da Resolução 196/96, do Conselho Nacional de Saúde (CNS).

\section{Resultados e discussão}

Os boletins do PCDCh forneceram informaçóes concretas e importantes para o presente projeto, tais como: o número de atividade realizadas; as espécies encontradas no município, o estágio desses vetores, assim como o local de captura. Além dessas informaçôes, foi possível também verificar o tipo de parede e teto das casas pesquisadas pelos Agentes de Controle de Endemias (ACE) durante o trabalho de campo.

Nesse sentido, vejamos o número de atividades realizadas pelos ACE, das quais consistem em: Pesquisa, Borrifação, Visita ao PIT sem notificação, Visita ao PIT com notificaçáo e atendimento a notificação. 
Figura 1 - Relação das atividades mensais realizadas no município de Santana de Pirapama com relação ao controle vetorial da doença de Chagas, no período entre novembro/2011 a julho/2012.

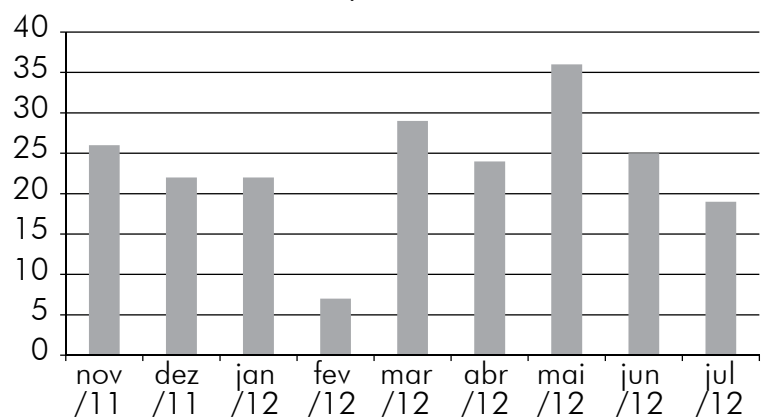

Fonte: Dados da Pesquisa.

Na Figura 1, podemos notar que, o mês de maio de 2012, foi o mais produtivo em termos de atividades. Já o mês de fevereiro foi o mais precário, segundo informaçóes do Serviço de Epidemiologia Municipal de Santana de Pirapama foi a falta de recursos materiais como o transporte para o meio rural, que dificultou o atendimento as notificaçóes, assim como as visitas ao PIT.

Figura 2 - Total de atividades realizadas para controle vetorial no município de Santana de Pirapama por PIT, conforme descrito no Diário de Pesquisa e Borrifação, no período compreendido entre novembro/2011 e julho/2012.

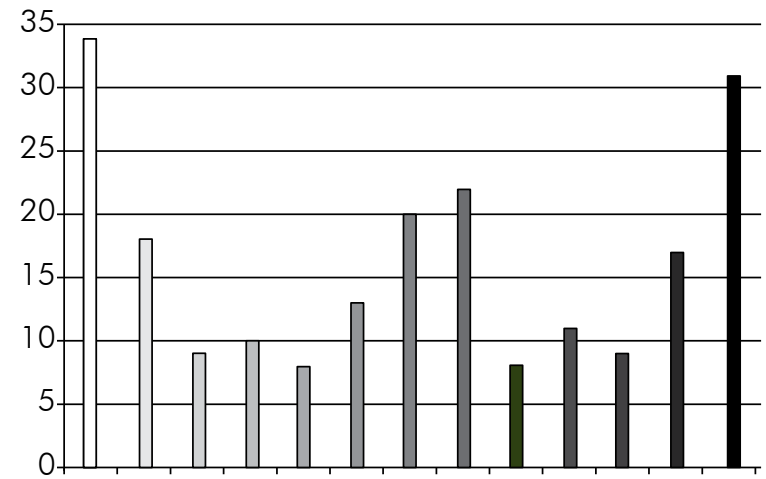

$\begin{array}{ll}\square \text { Inhames } & \square \text { Rio Preto } \\ \square \text { Ponte Cristal } & \square \text { Retiro D'antas } \\ \square \text { São José dos Moreiras } & \square \text { Fechados } \\ \square \text { Tibuna } & \square \text { Curralinho } \\ \square \text { Tibuna de Cima } & \square \text { Guariba } \\ \square \text { Passatempo } & \square \text { Cidade }\end{array}$

Fonte: Dados da Pesquisa.

No Figura 2, percebe-se que foi o PIT de Inhames o que mais produziu desde a implantação desses PIT, seguido por Santana de Pirapama e depois Rio
Preto. Ficando os que menos receberam algum tipo de atividade o PIT da Tibuna de Cima e o PIT do Retiro D'antas (Chuvinha).

Outra informação fornecida foram os tipos de parede e teto, que conforme no boletim pode ser: Alvenaria com Reboco, Alvenaria sem Reboco, Barro com Reboco, Barro sem Reboco, Madeira e Outros. E os tipos de parede foram descritos da seguinte maneira: Telha, Palha, Madeira, Metálico, Outros.

Figura 3 - Relação dos tipos de paredes e tetos encontrados, conforme descrito no Diário de Pesquisa e Borrifação utilizados pelos Agentes de Campo no Município de Santana de Pirapama, no período entre novembro/2011 e julho/2012.

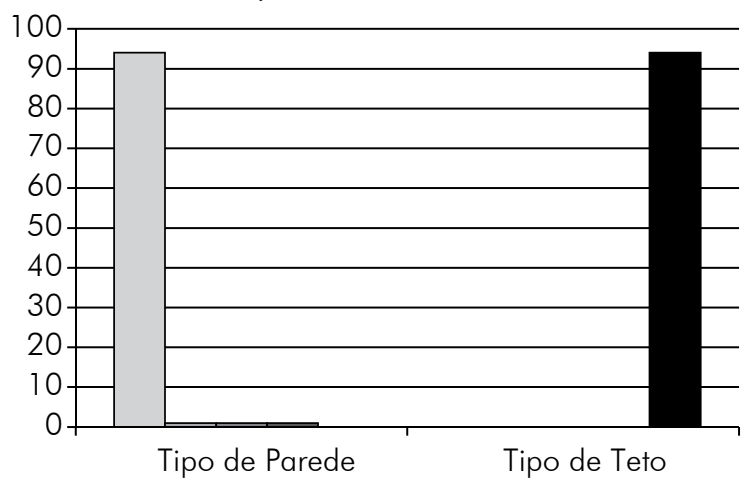

$$
\begin{aligned}
& \square \text { Alvenaria Com Reboco } \square \text { Barro Sem Reboco } \\
& \square \text { Alvenaria Sem Reboco } \square \text { Telha } \\
& \square \text { Barro com Reboco }
\end{aligned}
$$

Fonte: Dados da Pesquisa. Obs.: Só foram colocados na tabela os campos que estavam marcados no boletim. Muitos boletins estavam com campos em branco.

Na Figura 3, notamos que 97\% das casas pesquisadas no Município de Santana de Pirapama são de alvenaria com reboco, mas é importante observar que ainda há moradia ativa de barro sem reboco. As casas de barro, geralmente, possuem má iluminação, possuem buracos e frestas, o que favorece a estadia do Triatomíneo [12].

$\mathrm{O}$ agente causador da doença de Chagas vivia somente em ambientes silvestres, entre os mamíferos. Com a evolução do homem na terra, este invadiu esses ambientes, ou seja, os ecótopos, passando a fazer parte do ciclo epidemiológico da doença de Chagas, pois, favoreceu os abrigos aos triatomíneos transmissores da doença, como: casas de pau-a-pique, construídas de barro e madeira [13]. 
Outro dado foi com relação à captura do inseto, que pode ser no intradomicílio, tendo como local de captura, a sala, o quarto, a cozinha ou outros. A presença de triatomíneos no intradomicílio favorece o contato do homem com o Triatomíneo, aumentando as chances de infecçáo pela doença de Chagas, uma vez que, se há presença do vetor, pode haver risco desses insetos estarem infectados pelo T. cruzi [12].

Os triatomíneos permanecem durante os dias alojados em buracos, frestas, por baixo de colcháo, e em vários outros lugares que juntem entulho, sendo assim o Triatomíneo tem preferência por sair à noite, quando saem para se alimentarem, ou seja, realizar o repasto sanguíneo, que poderá logo após esse momento defecar e no caso de o inseto estiver infectado por esse protozoário, a vítima irá contrair a doença de Chagas [12].

Tabela I - Relação de capturas de Triatomíneos, assim como local de captura no Intradomicílio no município de Santana de Pirapama, no período entre outubro/2011 a julho/2012.

\begin{tabular}{lccc}
\hline \multicolumn{1}{c}{ PIT } & Sala & Cozinha & Quarto \\
\hline Inhames & 01 & & 01 \\
Ponte Cristal & 02 & 01 & \\
Tibuna & & 01 & \\
$\begin{array}{l}\text { Passatempo } \\
\text { Duas Barras }\end{array}$ & 01 & & 03 \\
Rio Preto & & 01 & 05 \\
Fechados & 02 & & 02 \\
$\begin{array}{l}\text { Guariba } \\
\text { Santana de Pira- } \\
\text { pama }\end{array}$ & 03 & & 04 \\
TOTAL & 09 & 03 & 15 \\
\hline
\end{tabular}

Fonte: Dados da Pesquisa. Obs.: Só foram incluídos na Tabela I, os PIT com notificação. Todos os Triatomíneos capturados são identificados por etiqueta enumerada.

Nota-se que na Tabela I, no intradomicílio, ou seja, dentro do domicílio, o quarto é local preferido pelos Triatomíneos, chegando num percentual de $55,6 \%$, e conforme informado nos boletins são comumente encontrados debaixo de colchóes, seguido pela sala com $33,3 \%$ e por último a cozinha com $11,1 \%$.

Os Triatomíneos podem ser transportados para o intradomicílio por meio de cascas de madeiras, ou seja, nas lenhas quando essas são levadas para o intradomicilio para acender fogo, outra maneira, pode ser pelos animais domésticos que habitam no peridomicílio, e a partir daí habitando dentro das moradias [12].

As más condiçôes das casas propiciam a infestação pelo T. Cruzi, que se adaptam com o passar de sua evoluçáo aos domicílios. As casas de pau-a-pique de adobe sem reboco, entre outras, se faz importante nesses casos. Já as paredes rebocadas, sem frestas, dificulta a estadia do Triatomíneo. Entretanto é preciso priorizar quando há ecótopos naturais e espécies nativas presentes nesse ambiente [3].

Agora, pela pesquisa se a captura aconteceu no peridomicílio, pode ter sido no galinheiro, chiqueiro, paiol ou outros.

Tabela II - Relação de capturas de Triatomíneos, assim como local de captura no Peridomicílio, conforme descrito no Diário de Pesquisa e Borrifação no município de Santana de Pirapama, no período entre novembro/2011 e julho/2012.

\begin{tabular}{lccc}
\hline \multicolumn{1}{c}{ PIT } & Galinheiro & Paiol & Outros \\
\hline Inhames & 09 & & \\
Ponte Cristal & 03 & & \\
Passatempo & 01 & & \\
Duas Barras & 04 & 02 \\
Guariba & 02 & 01 & 01 \\
Santana de Pira- & 07 & 03 \\
pama & 26 & 03 \\
TOTAL & & 03 \\
\hline $\begin{array}{l}\text { Fonte: Dados da Pesquisa. Obs.: Só foram incluídos na tabela, } \\
\text { os PIT com notificação no peridomicílio. Todos os Triatomíneos }\end{array}$ \\
capturados são identificados por etiqueta enumerada.
\end{tabular}

$\mathrm{Na}$ Tabela II, o galinheiro é o destaque, com $81,25 \%$ das notificaçóes atendidas, restando apenas $9,375 \%$ para o paiol e $9,375 \%$ para outros, como chiqueiro e curral. Em um estudo realizado por Teixeira [14], as infestaçóes por Triatomíneo aconteceram no peridomicílio, nos galinheiros, montes de madeira, locais onde guardam palhas e amontoados de rochas.

O galinheiro, assim como o curral e demais anexos existentes em um domicílio e periurbano, é um local muito visitado por determinados animais como: quatis, tatus, mucuras, que podem estar servindo como fonte de infecção aos triatomíneos existentes nos peridomicílios, e a partir daí infectando esses insetos e esses repassando a infecção ao homem [3].

Outro boletim do PCDCh é o que fica no invólucro da embalagem de armazenagem do inseto com alguns dados de identificação como: o Número 
do PIT; a Localidade/RG do PIT; a Superintendência Regional de Saúde - SRS; o Município; a Localidade de Notificação; o Número de Insetos capturados Dentro de Casa e Fora de Casa; o Local de Captura; o Nome do Morador; o Número da (SUS); o Nome do Capturador; o tipo de inseto, se foi Barbeiro, Outros ou Não Sabe; e a Data de Recebimento pelo Colaborador. Esse boletim não foi verificado, uma vez que esse documento é encaminhado junto ao Triatomíneo para o Laboratório.

Os formulários emitidos do laboratório, após a identificação da espécie e do exame, trazem os dados de identificaçáo como: número da etiqueta; a data do exame; o responsável pelo exame. E sobre o exame dos triatomíneos consta: o código e o nome da espécie de triatomíneo; se a captura foi no intra ou peridomicílio; se estágio em que se encontrou o triatomíneo foi ninfa, adulto macho ou adulto fêmea; e o resultado do exame se foi positivo, negativo ou náo examinado.

Figura 4 - Resultados dos exames de Triatomíneos, assim como a espécie e estágio do inseto, conforme descrito no Formulário de Exame de Triatomíneos do Programa de Controle da Doença de Chagas - PCDCh.

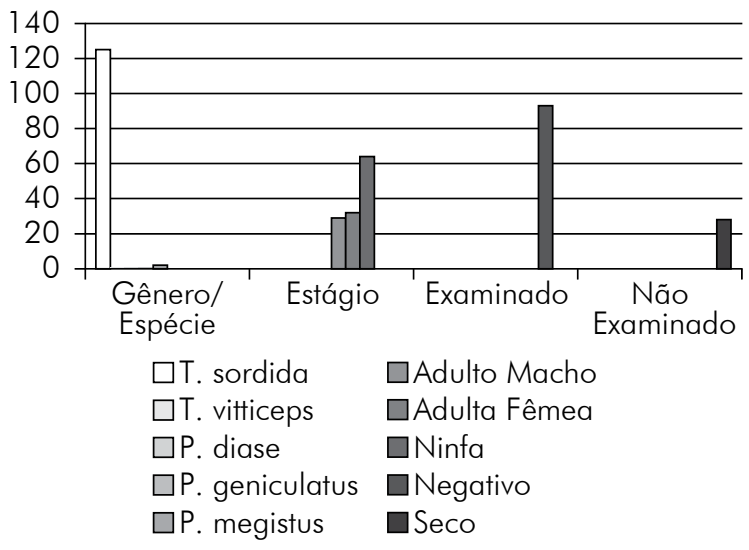

Fonte: Dados da Pesquisa.

Triatomíneos encaminhados para o Laboratório da Superintendência Regional de Saúde de Sete Lagoas para identificação e exames.

De acordo com a Figura 4, a espécie mais comumente encontrada no município de Santana de Pirapama é o Triatoma sordida, representando um percentual de 96,15\% dos triatomíneos capturados.

No Brasil, o T. sordida é mais comumente encontrada no peridomicílio. Essa espécie está fortemente ligada aos quintais, onde há presença de cascas de árvores, galinhas, além dos anexos, como paióis, chiqueiros e currais [15].
Duas importantes espécies na transmissão da Doença de Chagas são o T. sordida e o Panstrongylus megistus [3]. Esse último representa 1,54\% dos triatomíneos encontrados no município de Santana de Pirapama de acordo com a pesquisa documental. $\mathrm{O}$ T. sordida e o P. megistus gostam de estar associados a hospedeiros terrestres [3].

Já o Triatoma vitticeps, Panstrongylus diase e Pantrongylus geniculatus, ambos representaram $0,77 \%$. As espécies como o Triatoma vitticeps, comumente encontrados nos estados do Rio de Janeiro e Espírito Santo merecem destaque por apresentar altas taxas de infecção natural, e o P. geniculatus é uma espécie muito encontrada na Amazônia [3], também associada à habitaçáo periurbana e o $P$. diase, está intimamente ligada a ambientes silvestres [16].

Em Santana de Pirapama, foram 130 Triatomíneos notificados no período da pesquisa, desses, o estágio de ninfa foi a mais encontrada. Segundo Gonçalves e Costa [17], o período de resistência com relaçáo ao jejum é maior nas ninfas que estáo no $5^{\circ}$ estágio, podendo variar entre 58 e 217 dias. Essa resistência pode favorecer que escapem dos químicos utilizados para o controle desses vetores, permitindo a reinfestação dessas casas.

Outros insetos pesquisados nos documentos, não foram examinados, pois chegam ao laboratório morto ou já seco. Mas a maioria dos Triatomíneos encaminhados para o laboratório é examinado e, de acordo com a pesquisa, nenhum Triatomíneo deu positivo para Tripanosoma cruzi neste período.

O PIT da cidade, por ser o PIT central, já era de se esperar que fosse o que receberia mais notificaçôes. Portanto, foi o que mais recebeu Triatomíneo, isso acontece por que o inseto é trazido pelo morador diretamente ao PIT Central em vez de entregar no seu PIT de referência, ficando assim a entrada no PIT da cidade.

\section{Conclusão}

Foi surpreendente a quantidade de Triatomíneos capturados durante as atividades do PIT. Esse dado mostrou que foram efetivas as açóes do PIT para o controle vetorial no município de Santana de Pirapama/MG.

Os resultados foram satisfatórios em se tratando dos tipos de moradias existentes no município de Santana de Pirapama. Contudo, ainda há famílias que vivem em situação de risco, onde o ambiente e presença de hospedeiro no T. cruzi está presente. 
Figura 5 - Números de Triatomíneos notificados por PIT no período de novembro/2011 a julho/2012.

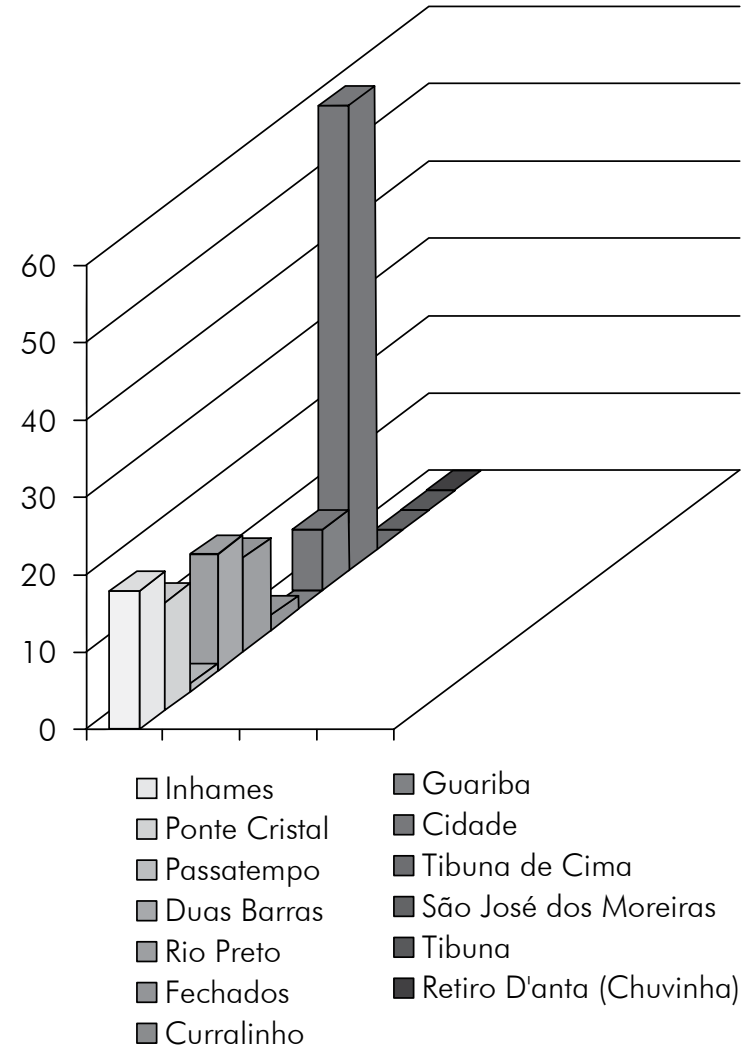

Fonte: Dados da Pesquisa.

Foi notável que a participação popular fosse imprescindível para que o município de Santana de Pirapama saísse desse estado de estagnação de atividades para controle vetorial da doença de Chagas. Assim foram os resultados diante de uma população carente que vive em local de médio risco de reinfestação vetorial da doença de Chagas.

Alguns itens com certeza serão fundamentais para manter essa estratégia ativa, como a contratação de mais Agentes de Controle de Endemias, a disponibilidade de veículos para o transporte dos Agentes e da carga utilizada para atendimentos de pesquisa e borrifação e de uma motocicleta para visita mensal aos PIT.

Uma ação viável para todas as localidades será a adoção de estratégias acerca dos galinheiros e quartos que, de acordo com a pesquisa, são os locais onde mais se captura Triatomíneos, um meio poderia ser a divulgação em radiodifusão e fixação de cartazes em ônibus rurais sobre os cuidados que se deve ter com galinheiros, e o incentivo a construção de galinheiros a base de tela e telha de amianto. Outras açôes são as medidas de higiene, para que o colchão seja colocado no sol pelo menos de $15 \mathrm{em} 15$ dias.
Acredito que o trabalho de Educação em Saúde nas zonas rurais, seja por reunião coletiva, seja de casa em casa, por meio do Agente Comunitário de Saúde (ACS) deverá ser uma rotina diária para que seja mantido o que já alcançou para o controle vetorial da Doença de Chagas no município de Santana de Pirapama/MG.

\section{Referências}

1. Ministério da Saúde. Vigilância em Saúde: Zoonoses. Brasília: Ministério da Saúde; 2009.

2. Ministério da Saúde. Guia de Vigilância Epidemiológica. 5a ed. Brasília: Ministério da Saúde; 2002.

3. Ministério da Saúde. Guia de Vigilância Epidemiológica. 7a ed. Brasília: Ministério da Saúde; 2010. 810p.

4. Carneiro M, Antunes CMF. Avaliaçáo de eficácia do programa de controle da doença de chagas: aspectos metodológicos. Cad Saúde Pública 1994;10(2):261-72.

5. Moreno EC, Baracho L. Vigilância epidemiológica no Programa de Controle da Doença de Chagas em Minas Gerais, Brasil (1984-1998). Cad Saúde Pública 2000;16(2):113-6.

6. Bedin C, Mello F. Manual do PIT: Posto de Informação de Triatomíneo. Brasília: Rio Grande do Sul; 2009.

7. IBGE (Instituto Brasileiro de Geografia e Estatística). IBGE Cidades @: Santana de Pirapama - MG, 2010. [citado 2012 Jun 18]. Disponível em URL: www. ibge.gov.br

8. AMAV (Associação dos Municípios do Alto Rio das Velhas). Dados dos Municípios: Santana de Pirapama, 2012. [citado 2012 Jun 18]. Disponível em URL: http://www.amav.mg.gov.br/spirapama.htm

9. Santos EGR. Santana de Pirapama - Minas Gerais, 2012. [citado 2012 Nov 4]. Disponível em: URL: www. mapasbrasil.net/santana-de-pirapama_minas-gerais.html.

10. Brasil. Secretaria de Estado da Saúde. Estratégia para Programação da PPI-VS no Programa de Controle da Doença de Chagas - PCDCh. Minas Gerais, 2006. [citado 2012 Mar 25]. Disponível em URL: www. bvsms.saude.gov.br/

11. Marconi MA, Lakatos EM. Fundamentos de Metodologia Científica. 6a ed. São Paulo: Atlas; 2005.

12. Argolo AM, Felix M, Pacheco R, Costa J. Doença de Chagas e seus principais vetores no Brasil. Rio de Janeiro: Ministério da Saúde; 2007.

13. Vinhaes MC, Dias JCP. Doença de Chagas no Brasil. Cad Saúde Pública 2000;16(2):7-12.

14. Teixeira NFD. Estudo da Fauna de Triatomíneos em uma localidade rural do município de Russas, Ceará [Dissertação]. Rio de Janeiro: Instituto Oswaldo Cruz; 2011.

15. Diotaiuti L, Azeredo BVM, Uber Busek SC, Fernandes AJ. Controle do Triatoma sordida no peridomicílio rural do município de Porteirinha, Minas Gerais, Brasil. Rev Panam Salud Pública 1998;3(1):21-5.

16. Rebelo JMM, Barros VLB, Mendes WA. Espécies de Triatominae (Hemiptera: Reduviidae) do Estado do Maranhão, Brasil. Cad Saúde Pública 1998;14(1):187-92.

17. Gonçalves TCM, Costa J. Biologia dos Vetores da Doença de Chagas. Rio de Janeiro: Fiocruz; 2012. 